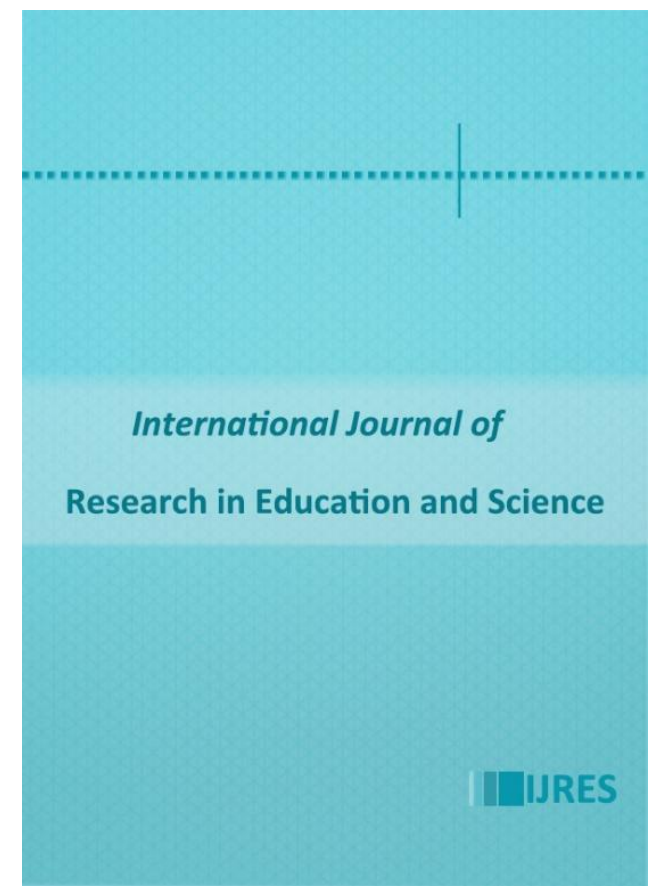

\title{
International Journal of Research in Education and Science (IJRES)
}

\section{www.ijres.net}

An Exploratory Survey on Teaching Practices Integrating Nutrition and Mathematics in Australian Primary Schools

Berit M. Follong ${ }^{1,2}$, Elena Prieto-Rodriguez ${ }^{3}$, Andrew Miller $^{3}$, Clare E. Collins ${ }^{1,2}$ Tamara Bucher ${ }^{1,2}$

${ }^{1}$ School of Health Sciences, University of Newcastle, Australia ${ }^{2}$ Priority Research Centre for Physical Activity and Nutrition, University of Newcastle, Australia

${ }^{3}$ School of Education, University of Newcastle, Australia

ISSN: 2148-9955

\section{To cite this article:}

Follong, B.M., Prieto-Rodriguez, E., Miller, A., Collins, C.E., \& Bucher, T. (2020). An exploratory survey on teaching practices integrating nutrition and mathematics in Australian primary schools. International Journal of Research in Education and Science (IJRES), 6(1), 14-33.

The International Journal of Research in Education and Science (IJRES) is a peer-reviewed scholarly online journal. This article may be used for research, teaching, and private study purposes. Authors alone are responsible for the contents of their articles. The journal owns the copyright of the articles. The publisher shall not be liable for any loss, actions, claims, proceedings, demand, or costs or damages whatsoever or howsoever caused arising directly or indirectly in connection with or arising out of the use of the research material. All authors are requested to disclose any actual or potential conflict of interest including any financial, personal or other relationships with other people or organizations regarding the submitted work. 


\title{
An Exploratory Survey on Teaching Practices Integrating Nutrition and Mathematics in Australian Primary Schools
}

\author{
Berit M. Follong, Elena Prieto-Rodriguez, Andrew Miller, Clare E. Collins, Tamara Bucher
}

\begin{tabular}{|c|c|}
\hline Art & DS \\
\hline pry & \multirow{9}{*}{$\begin{array}{l}\text { Overweight and obesity prevalence in children has increased worldwide. One } \\
\text { factor contributing to this rise is the increase in portion sizes, with individuals } \\
\text { potentially having difficulties with portion size estimation. Portion size } \\
\text { estimation could be improved with portion size education involving the } \\
\text { mathematical concepts of volume and capacity. The current study aimed to } \\
\text { explore mathematical teaching practices related to volume and capacity } \\
\text { measurement in Australian primary schools, with a focus on use of nutrition } \\
\text { related examples and technology. A convenience sample of } 101 \text { teachers } \\
\text { completed an online exploratory survey reporting information on their teaching } \\
\text { background, experience, use of resources, digital games and curricular } \\
\text { integration. Results indicated that the teachers surveyed favoured use of } \\
\text { Smartboards and cubes to teach volume and capacity, and the majority reported } \\
\text { using nutrition-related examples including household measures, recipes and } \\
\text { grocery shopping. They also expressed having positive beliefs and interest in } \\
\text { using digital games for teaching these concepts. Although mathematics is most } \\
\text { commonly integrated with science and technology, the teachers surveyed } \\
\text { indicated that a digital game integrating nutrition and mathematics could be very } \\
\text { useful. There is potential to investigate ways to integrate portion size estimation } \\
\text { activities within mathematics teaching practices which can be facilitated using } \\
\text { digital games. }\end{array}$} \\
\hline r 2018 & \\
\hline 019 & \\
\hline Keywords & \\
\hline & \\
\hline & \\
\hline & \\
\hline & \\
\hline & \\
\hline
\end{tabular}

\section{Introduction}

Childhood overweight and obesity prevalence has steadily increased in both developed and developing countries (Sahoo et al., 2015). In Australia, over 60 percent of adults and 27 percent of children aged 5-17 years have overweight or obesity (Australian Institute of Health and Welfare, 2017). These children are at increased risk of developing chronic diseases such as diabetes or cardiovascular disease (CVD). Not only does this impact children at a young age, they are also more likely to remain overweight or obese in adulthood (Sahoo et al., 2015). This clearly indicates that there is a major public health problem, and a need for early interventions. The present study aimed to explore primary school teaching practices related to the integration of nutrition with mathematics education with a specific focus on portion size and, volume and capacity, and the use of technology to facilitate teaching in these areas. The increase in food portion sizes is one factor contributing to the rise in prevalence of overweight and obesity (Young \& Nestle, 2007). A review identified that energy-dense, nutrientpoor foods have specifically increased over the past decades, with larger portion sizes served by fast-food companies (Steenhuis \& Vermeer, 2009). A recent study explored portion size changes in selected Australian foods amongst children aged 2-17 years between National Nutrition Surveys in 2007 and 2011-2012. They found an increase in mean portion size for several energy-dense, nutrient-poor foods, while vegetable and fruit portion sizes decreased (van der Bend et al., 2017). As portion size increases, individuals tend to consume more food and drinks, without being aware of the increase in intake (Hollands et al., 2015), leading to a subsequent increase in total energy intake (Wansink, 2004). Interventions including portion size education might be one potential strategy to reverse this trend in consumption of bigger portions and hence higher energy intakes (Steenhuis \& Vermeer, 2009; Young \& Nestle, 2012). Portion size estimation skills could help children develop knowledge, attitudes and behavioural skills needed to support healthy eating habits (Story, 1999). Both children and adults perceive portion and standard serve or serving size estimations as confusing (Bucher, Rollo, et al., 2017; Collins et al., 2015) with individuals struggling to accurately estimate food volume and portion size (Bucher, Weltert, et al., 2017; Nørnberg, Houlby, Jørgensen, He, \& Pérez-Cueto, 2014). However, research shows that adults and children are able to improve their estimation skills after receiving portion size education or training (Hausman, Borrero, Fisher, \& Kahng, 2017; Poelman, Steenhuis, de Vet, \& Seidell, 2013; Small, Lane, Vaughan, Melnyk, \& McBurnett, 2013). 
School environments play a key role in teaching children about healthy lifestyles and healthy eating (Agron, Berends, Ellis, \& Gonzalez, 2010; Pérez-Rodrigo \& Aranceta, 2003; Story, 1999; Strawser \& Wachob, 2016). A systematic review exploring the effect of different teaching strategies on the promotion of healthy eating in primary schools identified that experiential and cross-curricular approaches could positively influences nutrition behaviour (Dudley, Cotton, \& Peralta, 2015). According to the conceptual framework for cross-curricular teaching by Beckmann (2009), this type of teaching is defined as teaching within a discipline in which other subjects are integrated and subject boundaries are crossed. The integration of nutrition education within the curriculum has been proposed in several previous publications (Coulson, Eiser, \& Eiser, 1998; de Vlieger, Riley, Miller, Collins, \& Bucher, 2018; Eliassen \& Wilson, 2007; Hyman, 2008; James \& Adams, 1998; Perera, Frei, Frei, Wong, \& Bobe, 2015; Pérez-Rodrigo \& Aranceta, 2003; Stage, Kolasa, Díaz, \& Duffrin, 2018). Amongst a variety of subjects, most research has highlighted the potential for the integration of nutrition education within the mathematics curriculum. As reported by James and Adams (1998), a cross-curricular approach integrating nutrition and mathematics in primary schools could improve a child's nutrition knowledge and assist with the development of skills necessary to make healthy food choices. Simultaneously, it could contribute to a child's mathematical connections, problem solving, and reasoning, and support children in improving their procedural and conceptual mathematics knowledge.

During Year 3 and/or 4 of primary school, the Australian curriculum for Measurement and Geometry describes the introduction of children to using units of measurement (Australian Curriculum Assessment and Reporting Authority, 2019). Children learn to measure, compare and order objects using metric units such as length, mass, capacity, area and volume. Furthermore, they compare and describe key features of both two- and threedimensional objects. While these mathematical concepts on units of measurement might be essential, children appear to particularly struggle with estimating volume (Battista, 1999; Battista \& Clements, 1996; Tan Sisman \& Aksu, 2016). Battista (1996) found that primary school children often make mistakes when trying to enumerate units of cubes in order to measure volume. They commonly struggle with the concept of threedimensional objects and often confuse area with volume, double count cubes and are not able to take hidden cubes into account (Battista \& Clements, 1996; Tan Sisman \& Aksu, 2016). Basic mathematical skills are needed to accurately estimate portion size, understand food labels, cook and follow recipes (Hyman, 2008). When learning to estimate portion size, comparing different amounts of foods to standard measurement units or estimation aids, and to other foods is an essential skill (Trucil, Vladescu, Reeve, DeBar, \& Schnell, 2015; Weber et al., 1999). To be able to measure and compare food volumes, knowledge regarding mathematical measurements such as volume and capacity play an important role. Foods could be used as the objects selected to measure, compare and order different volumes and capacities, and for describing two- and three-dimensional shapes. This might therefore present an opportunity to provide education on portion size estimation of foods, within the mathematics curriculum.

Parallel to the proposed idea of mathematical skills being necessary for portion size estimation is the idea of integrating nutrition as a novel approach to make abstract mathematical concepts more meaningful and engaging. It is often reported that primary school children express negative thoughts towards mathematics (Attard, 2011, 2013; Larkin \& Jorgensen, 2015). Research shows that mathematical engagement has declined in Australian children in recent years (Attard, 2011, 2013). The importance of a decline in mathematics engagement should be acknowledged, as lack of engagement could disadvantage students' mathematics performance, possibly further impacting portion size estimation skills adversely (Australian Curriculum Assessment and Reporting Authority, 2009; Martin, Anderson, Bobis, Way, \& Vellar, 2012). Real-life examples have been suggested as potentially helpful to contextualize mathematical concepts (Attard, 2013; Australian Curriculum Assessment and Reporting Authority, 2009; Roseno et al., 2015; Sullivan, 2011; Wilkinson, Sullivan, \& Jorgensen, 2009). Including a connection to real-life applications, such as portion size estimation, is thought to play a key role in developing in-depth understanding of school subjects, while enhancing academic outcomes and learning enjoyment (Ladwig \& King, 2003). Introducing primary school children to nutritionrelated topics within mathematical subjects (Duffrin, Cuson, \& Phillips, 2005; James \& Adams, 1998; Roseno et al., 2015) such as statistics and probability, whole numbers, fractions, number sense, numeration, and measurement (James \& Adams, 1998) might therefore be useful. For example, food volumes could be compared to informal units such as cubes, or measured using measuring cups or graduated jugs. Whether integrated or not, previous studies have shown that the use of foods and/or nutrition education has a positive effect on mathematics knowledge and achievement (Roseno et al., 2015; Shilts, Lamp, Horowitz, \& Townsend, 2009).

However, cross-curricular strategies might not be sufficient to engage primary school children. Children today are "digital natives" who can be hard to engage using traditional instructional methods (Van Eck, 2006). To address this issue, there has been growing interest in use of digital games for teaching, as they can include 
motivational features, which may stimulate development of other useful skills (Connolly, Boyle, MacArthur, Hainey, \& Boyle, 2012). The term "game-based learning" has been used to classify games specifically designed for educational purposes, which could also promote engagement (Hainey, Connolly, Boyle, Wilson, \& Razak, 2016). Introducing educational games into the primary school curriculum has the potential to construct powerful learning environments in which active learning, problem-based learning and experiential learning can be supported (Oblinger, 2004). In addition, digital game-based learning makes academic content more interesting and enjoyable for "digital natives" (Prensky, 2003). For example, digital games such as Mathletics and Minecraft were found to be useful mathematics teaching tools, as they enable children to play whilst learning (Nansen, Chakraborty, Gibbs, Vetere, \& MacDougall, 2012; Schifter, Cipollone, \& Moffat, 2013). In the case of nutrition education, findings from the " 5 a Day" project identified that a nutrition intervention that included an educational videogame could improve school-aged children's eating habits and engagement (Rosi et al., 2015). A second study reported a positive impact of web-based computer-tailored nutrition education on awareness and motivation to change eating behaviour (Oenema, Brug, \& Lechner, 2001). The phenomenon "Digital GameBased Learning" could therefore be used to combine nutrition and mathematical content with children's motivation to play digital games (Prensky, 2003). The literature examined above indicates the need and prospects for curricular integration of portion size within mathematics teaching practices, and the potential for digital games to facilitate this integration. However, it is not known whether, or how, these practices are implemented in the current primary school classroom, nor what attitudes teachers have towards them. Therefore the aim of the current study is to explore practices for teaching mathematics in regard to volume and capacity measurement, and the integration of nutrition education outcomes within teaching. A secondary aim was to canvas Australian primary school teachers' perceptions on the likelihood of using digital technologies to facilitate this integration.

\section{Method}

\section{Design}

A cross-sectional study design was used to administer an exploratory online survey on current teaching practices in a national sample of teachers. The purpose of the survey was to obtain information on how teachers teach volume and capacity, use nutrition-related examples and use of technology. Results will inform future research and support the development of an integrated teaching resource combining volume estimation and nutrition, including a digital game.

\section{Participants}

This survey was directed to Australian primary school teachers. Teachers were eligible to participate if they were currently teaching or had taught Years 3 and/or 4 (children aged 8-10 years). These teachers were chosen as, according to the syllabus, they introduce children to volume and capacity in Years 3 and/or 4. Participants were recruited via a market research panel (Qualtrics, Provo, UT, USA). Respondents who were likely to qualify for the survey were randomly selected by Qualtrics panel partners. Potential respondents received an email invitation informing them on the length of the survey, available incentives and that the survey was for research purposes only. Specific details about the survey contents were not included in the invitation. Eligible teachers were able to complete the survey after giving their informed consent. Ethics approval was obtained from The University of Newcastle Human Research Ethics Committee (H-2018-0067).

\section{Data Collection}

Data was collected via an online survey conducted between March and May 2018 that was designed specifically to address the study aims. The survey was developed by an interdisciplinary expert team with researchers experienced in the areas of primary school Personal Development, Health and Physical Education; secondary school Mathematics; Nutrition and Consumer Behaviour; and Dietetics. Qualtrics software was used to create the online survey which consisted of 17 questions within four domains, to explore teaching practices used within mathematics education, with a specific focus on volume and capacity. The survey covered demographic characteristics, teaching experience, and questions related to use of teaching resources, digital games, integration of mathematics within other curricular subjects and additional comments. Given that the survey was exploratory in nature, it was not tested for reliability or validity. 


\section{Survey Domains}

\section{Demographic Characteristics and Teaching Experience}

The survey contained six questions regarding demographic characteristics and teaching experience. Demographic data included teacher's year of birth, gender and the Australian state in which their school was located. Further questions on teaching experience asked for years of teaching experience (' $0-2$ years', ' $3-5$ years', '6-10 years', '11-15 years' or '16+ years'), size of the school ('<100 students', '101-200 students', '201300 students', '301-400 students', '>400 students' or 'N/A') and type of school ('Government school', 'Nongovernment school (Catholic)', 'Non-government school (Independent)' or 'N/A'). These characteristics were not used in any further analyses. However, these outcomes were of importance in order to identify the representativeness of the study sample.

\section{Teaching Resources}

Two questions explored resources used to teach volume and capacity in primary schools. Participants were asked to indicate on a 7-point Likert-type scale ranging from never to 4-5 times a week, how often they use each of the 14 resources listed (e.g. 'Books', 'Video/film', 'PowerPoint slides', 'Online information websites/games', 'Cubes/blocks', 'Containers', 'Household measures', 'Liquids', 'Foods', 'Smartboards', 'Tablets/Ipads', 'Phones', 'Computers' and 'Other') to teach volume and capacity. A specific question examined whether participants reported having ever used any resources from a list of nutrition-related examples when teaching volume and capacity. Multiple answers could be ticked including 'Cooking/recipes', 'Household measures (e.g. measuring cups/spoons/pitchers)', 'Grocery shopping/supermarket products', 'Food labels', 'I don't usually use nutrition-related examples' and 'Other'.

\section{Digital Games}

This domain included three questions related to digital game usage. The first question was 'Do you make use of digital games when teaching volume and capacity?'. If the answer was yes, teachers were asked to specify the digital game. Other response options were; 'No, but I would like to make use of digital games', 'No, and I would not like to make use of digital games' or 'I don't know'. Next, teachers were requested to give their opinion in an open-ended question on what characteristics they would like in digital games designed to teach volume and capacity. Lastly, participants were asked whether they believed that digital games designed specifically for mathematics education could increase a child's achievement, learning enjoyment and knowledge on mathematics, using a 5-point Likert-type scale (yes - no) to record their responses.

\section{Cross-curricular Teaching}

Three questions covered the integration of mathematics lessons within other learning areas of the Australian curriculum. Participants were initially asked to answer either yes or no to the following question for each learning area; 'When teaching mathematics, do you integrate this with the following other learning areas of the Australian curriculum?'. When respondents answered 'yes', an open-ended question was shown asking which resources they used for each learning area. Moreover, teachers could rate their belief regarding the level of usefulness of a digital game integrating volume and capacity with nutrition as 'Extremely useful', 'Very useful', 'Moderately useful', 'Slightly useful' or 'Not at all useful'.

\section{Statistical Analysis}

All data was analysed using IBM SPSS Statistics Version 24 (IBM Corporation, 2016). Descriptive statistics were used to explore the data (means, standard deviations (SD), median, quartiles and percentages). Answers to open-ended questions were analysed using Excel. Response categories were identified in order to group similar answers. Individual responses were coded for these response categories and percentages were calculated to identify the most frequently reported response categories. 


\section{Results}

\section{Demographic Characteristics and Teaching Experience}

Results on demographic characteristics and teaching experience are summarised in Table 1. Over 100 teachers $(\mathrm{n}=101)$ completed the survey, of whom most were female $(80.2 \%)$, with a median age of 36.0 years (Interquartile range=30.0-44.5). The largest proportion (33.7\%) taught mathematics in New South Wales (NSW), followed by Queensland (QLD) and Victoria (VIC). Half of the teachers had up to five years of teaching experience, with almost 30\% teaching in schools larger than 400 students. With 63.4 percent, government schools were represented the most.

Table 1. Demographic Characteristics and Teaching Experience $(n=101)$

\begin{tabular}{|c|c|c|}
\hline $\begin{array}{l}\text { Demographic characteristics and teaching } \\
\text { experience }\end{array}$ & Median & (Interquartile range) \\
\hline \multirow[t]{2}{*}{ Age (years) } & 36.0 & $(30.0-44.5)$ \\
\hline & $\mathrm{N}$ & $\%$ \\
\hline \multicolumn{3}{|l|}{ Gender } \\
\hline Male & 20 & 19.8 \\
\hline Female & 81 & 80.2 \\
\hline \multicolumn{3}{|l|}{ State } \\
\hline Australian Capital Territory (ACT) & 4 & 4.0 \\
\hline New South Wales (NSW) & 34 & 33.7 \\
\hline Queensland (QLD) & 27 & 26.7 \\
\hline South Australia (SA) & 2 & 2.0 \\
\hline Victoria (Agron et al.) & 22 & 21.8 \\
\hline Western Australia (WA) & 12 & 11.9 \\
\hline \multicolumn{3}{|l|}{ Years of experience } \\
\hline 0-2 years & 25 & 24.8 \\
\hline $3-5$ years & 26 & 25.7 \\
\hline $6-10$ years & 22 & 21.8 \\
\hline 11-15 years & 11 & 10.9 \\
\hline $16+$ years & 17 & 16.8 \\
\hline \multicolumn{3}{|l|}{ Size of school } \\
\hline$<100$ students & 14 & 13.9 \\
\hline $101-200$ students & 19 & 18.8 \\
\hline 201-300 students & 18 & 17.8 \\
\hline $301-400$ students & 18 & 17.8 \\
\hline >400 students & 29 & 28.7 \\
\hline$N / A$ & 3 & 3.0 \\
\hline \multicolumn{3}{|l|}{ Type of school } \\
\hline Government school & 64 & 63.4 \\
\hline Non-government school (Catholic) & 11 & 10.9 \\
\hline Non-government school (Independent) & 24 & 23.8 \\
\hline N/A & 2 & 2.0 \\
\hline
\end{tabular}

\section{Teaching Resources}

Primary school teachers on average used Smartboards $(M=4.52, S D=1.56)$ and cubes/blocks $(M=4.48$, $\mathrm{SD}=1.45$ ) most frequently during the week when teaching volume and capacity (between once a week and 2-3 times a week) (Table 2). Conversely, food $(\mathrm{M}=3.28, \mathrm{SD}=1.55)$, video/film $(\mathrm{M}=3.27, \mathrm{SD}=1.49)$ and phones $(\mathrm{M}=3.00, \mathrm{SD}=1.01)$ were reported as being used less than once a week on average. 
Table 2. Likert-type Scale Survey Questions and Answers

\begin{tabular}{lll}
\hline Question & Sub-question & Mean $( \pm$ SD) score \\
\hline How often do you use the following resources & Smartboard & $4.52(1.56)$ \\
when teaching volume and capacity?* & Cubes/Blocks & $4.48(1.45)$ \\
& Books & $4.31(1.49)$ \\
& Containers & $4.23(1.57)$ \\
& Online information websites/games & $4.19(1.38)$ \\
& Household measures (e.g. measuring & $4.17(1.55)$ \\
& cups/spoons/pitchers) & \\
& Tablets/Ipads & $4.13(1.45)$ \\
& Liquids & $3.94(1.66)$ \\
& PowerPoint slides & $3.75(1.58)$ \\
& Computer & $3.68(1.62)$ \\
Do you believe that digital games designed for & Food & $3.28(1.55)$ \\
mathematics education in primary schools could & Learning enjoyment & $3.27(1.49)$ \\
increase a child's: $*$ & Kideo/film & $3.00(1.01)$ \\
& Knowledge about mathematics & $1.74(0.70)$
\end{tabular}

How useful do you believe it would be to have a digital game to integrate volume and capacity (within the Mathematics curriculum) with nutrition (within the Health and Physical Education curriculum)?***

*Response Likert-type scale: 1=Never, 2=Less than once a month, 3=1-3 times a month, 4=Once a week, 5=2-3 times a week, $6=4-5$ times a week. $* *$ Response Likert-type scale: $1=$ Definitely yes, $2=$ Probably yes, $3=$ Might or might not, 4=Probably not, 5=Definitely not. *** Response Likert-type scale: 1=Extremely useful, $2=$ Very useful, $3=$ Moderately useful, 4=Slightly useful, 5=Not at all useful

Only $5.0 \%(n=5)$ of the participants indicated that they did not usually use nutrition-related examples when teaching children about volume and capacity (Table 3). Regarding the other nutrition-related examples, most teachers reported using household measures $(84.2 \%, \mathrm{n}=85)$, followed by cooking/recipes $(65.3 \%, \mathrm{n}=66)$ and grocery shopping/supermarket products $(58.4 \%, \mathrm{n}=59)$.

Table 3. Multiple Choice Survey Questions and Answers

\begin{tabular}{lll}
\hline Question & Answer option & $\mathrm{N}(\%)$ \\
\hline $\begin{array}{l}\text { Do you use any of the following } \\
\text { nutrition-related examples when }\end{array}$ & Cooking/recipes & $66(65.3)$ \\
teaching volume and capacity? & Gousehold measures (e.g. measuring cups/spoons/pitchers) & $85(84.2)$ \\
& Food labels & $59(58.4)$ \\
& I don't usually use nutrition-related examples & $37(36.6)$ \\
Do you make use of digital games & Yes, I use the following digital game(s)... & $5(5.0)$ \\
when teaching volume and capacity? & No, but I would like to make use of digital games & $33(32.7)$ \\
& No, and I would not like to make use of digital games & $56(55.4)$ \\
& I don't know & $5(6.9)$ \\
\hline
\end{tabular}

\section{Digital Games}

The results indicate that over half of the teachers $(55.4 \%, \mathrm{n}=56)$ did not make use of digital games when teaching volume and capacity, but were interested in using them in the future (Table 3). Only a small number of teachers did not use digital games and indicated that they would not like to make use of them $(6.9 \%, \mathrm{n}=7)$. About five percent answered this question with 'I don't know' $(5.0 \%, \mathrm{n}=5)$. When using digital games $(32.7 \%$, $\mathrm{n}=33$ ), teachers frequently reported examples such as 'Mathletics', 'Cool Maths Games' and 'Study ladder'. Table 2 shows that, on average, teachers believed that digital games specifically designed for mathematical education in primary schools could increase a child's learning enjoyment $(M=1.40, S D=0.58)$, knowledge about mathematics $(\mathrm{M}=1.72, \mathrm{SD}=0.68)$ and achievement in mathematics $(\mathrm{M}=1.74, \mathrm{SD}=0.70)$ (on a Likert-type scale ranging from $1=$ 'Definitely yes' to $5=$ 'Definitely not'). Results from the open-ended question regarding game characteristics $(n=147)$ demonstrated that teachers would like to have a game, which is easy-to-use $(n=25)$, fun 
and engaging $(n=19)$ and makes use of real-life examples $(n=18)$. One of the participants reported on this latter game characteristic by writing 'I think that they [digital games] need to use concepts that children can relate to, for example, everyday objects, so that the concept has meaning for them'. Another teacher mentioned that the digital game should be 'easy to follow so students can access independently'. Please note that some responses contained multiple coded themes.

\section{Cross-curricular Teaching}

Mathematics is being integrated with several other learning areas of the Australian primary school curriculum (Table 4$)$. With both a total of $n=84(83.2 \%)$, Science and Technologies were most commonly reported as being integrated with mathematics (participants were able to tick multiple boxes). English was also observed as a popular learning area to integrate with mathematics (80.2\%). An open-ended question illustrated examples of resources used by teachers if they indicated integrating mathematics with another learning area. Within the Science curriculum, examples including "Environment", "Experiments", "Books" and "Online/Digital material" were described. For Technologies, examples, such as "Computer", "Tablet", "Smartboard" and "Online/Digital material" were reported most often. Lastly, teachers indicated on average that it would be very useful $(\mathrm{M}=1.83$, $\mathrm{SD}=0.88$ ) to have a digital game to integrate volume and capacity with nutrition education (on a Likert-type scale ranging from $1=$ Extremely useful to $5=$ Not at all useful).

Table 4. Integration of Mathematics into Other Curricular Subjects

\begin{tabular}{|c|c|c|c|}
\hline \multirow[b]{2}{*}{ Question } & \multirow[b]{2}{*}{ Sub-question } & \multicolumn{2}{|c|}{$\mathrm{N}(\%)$} \\
\hline & & Yes & No \\
\hline When teaching mathematics, do you & English & $81(80.2)$ & $20(19.8)$ \\
\hline integrate this with the following & Science & $84(83.2)$ & $17(16.8)$ \\
\hline other learning areas of the & Humanities and Social Sciences & $50(49.5)$ & $51(50.5)$ \\
\hline \multirow{4}{*}{ Australian curriculum? } & Arts & $51(50.5)$ & $50(49.5)$ \\
\hline & Technologies & $84(83.2)$ & $17(16.8)$ \\
\hline & Health and Physical Education & $61(60.4)$ & $40(39.6)$ \\
\hline & Languages & $28(27.7)$ & $73(72.3)$ \\
\hline
\end{tabular}

\section{Discussion}

Findings of the current online survey of Australian primary school teaching practices that focus on volume and capacity measurements indicate that teachers use Smartboards and cubes/blocks most frequently. They use other resources, such as food and phones, less commonly. Nutrition-related examples were reported as being used by the majority of teachers, with household measures favoured over cooking/recipes and grocery shopping/supermarket products. Most teachers either already used, or would like to make use of digital games, and believed digital games could improve knowledge, achievement and learning enjoyment of mathematics. Of all Australian curricular learning areas, mathematics lessons were integrated with Science and Technology most often. However, the idea of a digital game integrating nutrition with mathematics was perceived as potentially being very useful. Of the numerous types of resources available to teach volume and capacity, primary school teachers reported use of Smartboards and cubes/blocks most frequently. In general, the use of technology in the classroom for teaching mathematics has become popular (Bray \& Tangney, 2017), with Smartboards commonly present in the classroom in many countries, including Australia (Erdener \& Kandemir, 2018; Karsenti, 2016). In a study of mathematics teachers' attitudes towards use of Smartboards, researchers reported that teachers have positive attitudes and favour Smartboard use over the traditional whiteboard (Muhanna \& Nejem, 2013). Previous research indicates that the use of Smartboards or interactive whiteboards creates opportunities that lead to increases in student learning and engagement (Beeland, 2002; Cabus, Haelermans, \& Franken, 2017; Higgins, Beauchamp, \& Miller, 2007; Min \& Siegel, 2011; Önal, 2017). Thus, the frequent use of Smartboards might be an effective teaching strategy to positively impact students' mathematical learning experience.

Consistent with our findings, research indicates that cubes and blocks are traditional resources commonly used to teach children about measurement, including length, area, volume and spatial reasoning (Battista, 1999; Battista \& Clements, 1996; Dorko \& Speer, 2013; Tan Sisman \& Aksu, 2016; Verdine et al., 2014). Although these resources are frequently used, students appear to have some difficulties when estimating the volume of a three-dimensional array of cubes (Battista, 1999; Battista \& Clements, 1996; Tan Sisman \& Aksu, 2016). Primary school children find it hard to enumerate units of cubes in order to measure volume and make several common mistakes. These mistakes involve not taking hidden cubes into account, double counting of cubes and general confusion of area with volume (Battista \& Clements, 1996; Tan Sisman \& Aksu, 2016). A recent 
position paper by Bucher, Rollo, et al. (2017) discussed the use of a unit of cubes as a new food volume measurement aid for portion size education. This International Food Unit (IFU), consisting of eight smaller cubes, had the lowest mean estimation error compared to measuring cups, modelling clay and weight estimations when used to estimate multiple different food volumes (Bucher, Weltert, et al., 2017). This study shows promising results for the use of cubes to improve portion size estimation skills and simultaneously educate children on the mathematical concepts of volume and capacity. Hence, teachers should be made more aware of these common issues and future research should examine how nutrition may be used to overcome these difficulties when using cubes to estimate (food) volume.

By comparison, food and mobile phones were used less frequently when teaching volume and capacity. In line with our results, Carraway- Stage, Hovland, Showers, Díaz, and Duffrin (2015) reported that only a few programs use food as a teaching resource, despite the evidence supporting the use of food-based learning to educate children on mathematics and science (Stage et al., 2018). Food or valid food replicas (Bucher, van der Horst, \& Siegrist, 2012) could be effective resources because children encounter food every day, food can be used as a hands-on and inquiry-based concept, and it has the potential as cross-curricular approach to teach many different educational subjects (Calder, Brawley, \& Bagley, 2003; Duffrin et al., 2010). In addition, mobile or smart phone use has rapidly risen, with over $60 \%$ of the worldwide population using a phone every day (Statista, 2016). This rise has led to an increased use of applications (apps) for a range of purposes, including education (Bano, Zowghi, Kearney, Schuck, \& Aubusson, 2018). Although research supports the benefits of using mobile learning in schools, it has been shown that this knowledge has not been effectively applied in educational settings (Milrad et al., 2013; Selwyn, 2010). Several challenges and barriers could explain why mobile phone usage is low amongst teachers. For example, financial restrictions, lack of hardware resources, lack of skilled teachers and educational policies to effectively implement mobile learning, privacy issues and parental reservations on the extended use of mobile devices by children (Tsinakos \& Ally, 2013; Yu, Lee, \& Ewing, 2014). These results clearly highlight the gap between research and practice on the use of food and mobile phones for teaching.

Although teachers do not use food to teach volume and capacity, the majority do make use of other nutritionrelated examples, such as household measures, cooking/recipes and grocery shopping/supermarket products. Earlier evidence on use of these examples in the mathematics classroom is lacking. Only one article in a teaching journal, published in 1991, was found in which the use of cooking and grocery shopping to teach mathematics was reported (Saathoff, 1991). Results from a food-based science (FoodMASTER) program indicate that not only mathematical engagement, but also overall mathematics and nutrition knowledge, increased following the use of household measures and recipes to teach primary school children about several mathematical topics, including measurement (Carraway- Stage et al., 2015; Roseno et al., 2015). This type of program might be effective because it creates a context in which children learn about mathematical concepts with real-life and relevant examples. In this way, children might be more engaged and this could make mathematics more meaningful (Attard, 2013; Australian Curriculum Assessment and Reporting Authority, 2009; Roseno et al., 2015; Sullivan, 2011).

We found that more than half of mathematics teachers do not use, but are interested in using digital games. This is in agreement with research from De Grove, Bourgonjon, and Van Looy (2012), who highlighted that although there is ample research on the potential and interest in digital games, the actual implementation of these games remains limited. Teachers also believe digital games could improve knowledge, achievement and learning enjoyment in mathematics. In line with teachers' beliefs, research indicated that digital games can be used to enhance motivation, engagement and enjoyment while providing compelling learning environments in which specific mathematical content can be taught (Lowrie \& Jorgensen, 2015; Vu \& Feinstein, 2017). A recent study by Fokides (2018) observed that primary school children performed better on mathematical learning outcomes when using digital games compared to conventional teaching and that the students experienced the games as being fun and enjoyable. In order to effectively implement digital games in the primary school classroom, teachers need to support the thought that these tools can be valuable for learning and for teaching (Dickey, 2015). Overall, these results indicate that there is room for improvement regarding the use of digital games within mathematical lessons, given teachers are interested and have positive believes towards this educational tool, and previous research provides some evidence for its effectiveness.

An important characteristic of successful school-based nutrition education programs is the provision of adequate time (Pérez-Rodrigo \& Aranceta, 2001). Currently, the curriculum is very crowded and teachers report a lack of time as a major barrier for teaching nutrition education (Agron et al., 2010; de Vlieger et al., 2018; Jones \& Zidenberg-Cherr, 2015; Perikkou, Kokkinou, Panagiotakos, \& Yannakoulia, 2015). We observed that, when integrated, it is less common to teach mathematics through the Health and Physical Education curriculum. 
Mathematics is integrated with Science and Technology most commonly. A possible explanation for this might be the concept of STEM education in which curricular subjects Science, Technology, Engineering and Mathematics are all integrated. In 2015, all Australian states agreed on the National STEM School Education Strategy 2016-2026 to promote the development of problem solving, critical analysis and creative thinking skills (Education Council, 2015). Early implementation to engage children with STEM in primary school is of importance due to the declining numbers of students continuing into higher STEM education (Tytler, Osborne, Williams, Tytler, \& Cripps Clark, 2008; Wall, 2016). As our results show that it is uncommon for mathematics to be integrated with Health and Physical Education, increasing the use of nutrition-related examples such as portion size estimation can potentially broaden the scope of mathematics usability in everyday life for the children and help overcome the time barrier to teach about nutrition.

\section{Strengths and Limitations}

A strength of the current study is that to our knowledge, teaching practices on mathematical content and concepts related to volume and capacity in primary school classrooms have not been examined previously, particularly in relation to nutrition and use of digital resources. Although the sample size was small, the population is broadly representative of Australian primary school teachers and this exploratory paper provides new knowledge on the gap between current research and practice. Given the reliability and validity of the survey has not been evaluated, results should be interested with caution.

\section{Conclusions, Recommendations and Further Research}

The current study provides insights into teaching practices within Years 3 and 4 in regard to education on mathematics (volume and capacity) and its integration with nutrition used by Australian primary school teachers. Importantly, our research shows that there are opportunities for improving the integration of nutrition and mathematics education and the use of technology in primary schools. Using real-life examples, such as foods and nutrition-related topics to teach mathematics, has the potential to contextualize mathematical concepts to everyday scenarios, with basic mathematical skills fundamental to understand food labels, recipes and portion size estimation. Thus, our findings suggest that cross-curricular education on portion size and measurement should be promoted among primary school teachers as this might be beneficial for both healthy eating and mathematics engagement in children. Additionally, teachers should be supported to use technology-based games integrating both subject areas to create optimal learning environments, which increase mathematical engagement. Future research should examine the development and implementation of cross-curricular resources using technology and investigate acceptability and effectiveness in improving portion size estimation and measurement skills.

\section{Acknowledgements}

None of the authors had any conflicts of interest in writing this article. We acknowledge all participants contributing to the input for this study. This study was supported by the School of Health Sciences and the Faculty of Health and Medicine of the University of Newcastle. Clare E. Collins is supported by a National Health and Medical Research Council of Australia Senior Research Fellowship and a Gladys M Brawn Senior Research fellowship from the Faculty of Health and Medicine, The University of Newcastle.

\section{References}

Agron, P., Berends, V., Ellis, K., \& Gonzalez, M. (2010). School wellness policies: Perceptions, barriers, and needs among school leaders and wellness advocates. Journal of School Health, 80(11), 527-535. doi:10.1111/j.1746-1561.2010.00538.x

Attard, C. (2011). "My favourite subject is maths. For some reason no-one really agrees with me": Student perspectives of mathematics teaching and learning in the upper primary classroom. Mathematics Education Research Journal, 23(3), 363-377. doi:10.1007/s13394-011-0020-5

Attard, C. (2013). "If I had to pick any subject, it wouldn't be maths": Foundations for engagement with mathematics during the middle years. Mathematics Education Research Journal, 25(4), 569-587. doi:10.1007/s13394-013-0081-8 
Australian Curriculum Assessment and Reporting Authority. (2009, May). Shape of the Australian curriculum: Mathematics. Retrieved from http://docs.acara.edu.au/resources/Australian_Curriculum_-_Maths.pdf

Australian Curriculum Assessment and Reporting Authority. (2019, January 14). Year 3 and 4 content descriptions: Measurement and Geometry. Retrieved from https://www.australiancurriculum.edu.au

Australian Institute of Health and Welfare. (2017). A picture of overweight and obesity in Australia 2017. Canberra: AIHW Retrieved from https://www.aihw.gov.au/getmedia/172fba28-785e-4a08-ab372da3bbae40b8/aihw-phe-216.pdf.aspx?inline=true.

Bano, M., Zowghi, D., Kearney, M., Schuck, S., \& Aubusson, P. (2018). Mobile learning for science and mathematics school education: A systematic review of empirical evidence. Computers \& Education, 121, 30-58. doi:10.1016/j.compedu.2018.02.006

Battista, M. T. (1999). Fifth graders' enumeration of cubes in 3D arrays: Conceptual progress in an inquirybased classroom. Journal for Research in Mathematics Education, 30(4), 417-448. doi:10.2307/749708

Battista, M. T., \& Clements, D. H. (1996). Students' understanding of three-dimensional rectangular arrays of cubes. Journal for Research in Mathematics Education, 27(3), 258-292. doi:10.2307/749365

Beckmann, A. (2009). A conceptual framework for cross-curricular teaching. The Mathematics Enthusiast, 6(4), $1-58$.

Beeland, D. (2002). Student engagement, visual learning and technology: Can interactive whiteboards help? Paper presented at the Annual Conference of the Association of Information Technology for Teaching Education.

Bray, A., \& Tangney, B. (2017). Technology usage in mathematics education research - A systematic review of recent trends. Computers \& Education, 114, 255-273. doi:10.1016/j.compedu.2017.07.004

Bucher, T., Rollo, M. E., Smith, S. P., Dean, M., Brown, H., Sun, M., \& Collins, C. (2017). Position paper on the need for portion-size education and a standardised unit of measurement. Health Promotion Journal of Australia, 28(3), 260-263. doi: 10.1071/HE15137

Bucher, T., van der Horst, K., \& Siegrist, M. (2012). The fake food buffet - a new method in nutrition behaviour research. British Journal of Nutrition, 107(10), 1553-1560. doi:10.1017/S000711451100465X

Bucher, T., Weltert, M., Rollo, M. E., Smith, S. P., Jia, W., Collins, C. E., \& Sun, M. (2017). The international food unit: A new measurement aid that can improve portion size estimation. International Journal of Behavioral Nutrition and Physical Activity, 14(1), 124. doi: 10.1186/s12966-017-0583-y

Cabus, S. J., Haelermans, C., \& Franken, S. (2017). SMART in Mathematics? Exploring the effects of in-classlevel differentiation using SMARTboard on math proficiency. British Journal of Educational Technology, 48(1), 145-161. doi:10.1111/bjet.12350

Calder, B., Brawley, S. H., \& Bagley, M. (2003). National Science Foundation graduate teaching fellows promote Food Science education in K- 12 schools in Maine. Journal of Food Science Education, 2(4), 58-60. doi: 10.1111/j.1541-4329.2003.tb00029.x

Carraway- Stage, V., Hovland, J., Showers, C., Díaz, S., \& Duffrin, M. W. (2015). Food- based science curriculum yields gains in nutrition knowledge. Journal of School Health, 85(4), 231-240. doi:10.1111/josh.12243

Collins, C. E., Bucher, T., Taylor, A., Pezdirc, K., Lucas, H., Watson, J., . . Burrows, T. (2015). How big is a food portion? A pilot study in Australian families. Health Promotion Journal of Australia, 26(2), 83-88. doi: 10.1071/HE14061

Connolly, T. M., Boyle, E. A., MacArthur, E., Hainey, T., \& Boyle, J. M. (2012). A systematic literature review of empirical evidence on computer games and serious games. Computers \& Education, 59(2), 661-686.

Coulson, N. S., Eiser, C., \& Eiser, J. R. (1998). Nutrition education in the National Curriculum. Health Education Journal, 57(1), 81-88.

De Grove, F., Bourgonjon, J., \& Van Looy, J. (2012). Digital games in the classroom? A contextual approach to teachers' adoption intention of digital games in formal education. Computers in Human Behavior, 28(6), 2023-2033. doi: 10.1016/j.chb.2012.05.021

de Vlieger, N., Riley, N., Miller, A., Collins, C. E., \& Bucher, T. (2018). Nutrition education in the Australian New South Wales primary school curriculum: An exploration of time- allocation, translation and attitudes in a sample of teachers. Health Promotion Journal of Australia. doi:10.1002/hpja.188

Dickey, M. D. (2015). K-12 teachers encounter digital games: A qualitative investigation of teachers' perceptions of the potential of digital games for K-12 education. Interactive Learning Environments, 23(4), 485-495. doi:10.1080/10494820.2013.788036

Dorko, A., \& Speer, N. M. (2013). Calculus students' understanding of volume. Investigations in Mathematics Learning, 6(2), 48-68. doi: 10.1080/24727466.2013.11790332

Dudley, D. A., Cotton, W. G., \& Peralta, L. R. (2015). Teaching approaches and strategies that promote healthy eating in primary school children: A systematic review and meta-analysis. International Journal of Behavioral Nutrition and Physical Activity, 12(1), 28. 
Duffrin, M. W., Cuson, D., \& Phillips, S. K. (2005). Using food to boost math and science skills. Journal of Family and Consumer Sciences, 97(1), 64-65.

Duffrin, M. W., Hovland, J., Carraway-Stage, V., McLeod, S., Duffrin, C., Phillips, S., . . . Berryman, D. (2010). Using food as a tool to teach science to 3rd grade students in Appalachian Ohio. Journal of Food Science Education, 9(2), 41-46. doi:10.1111/j.1541-4329.2010.00090.x

Education Council. (2015, December). National STEM school education strategy: A comprehensive plan for science, technology, engineering and mathematics education in Australia. Retrieved from http://www.educationcouncil.edu.au/site/DefaultSite/filesystem/documents/National\%20STEM\%20Scho ol\%20Education\%20Strategy.pdf

Eliassen, E. K., \& Wilson, M. W. (2007). Selecting appropriate elementary school nutrition education resources. American Journal of Health Studies, 22(4).

Erdener, K., \& Kandemir, M. A. (2018). Investigation of the reasons for students' attitudes towards the interactive whiteboard use in mathematics classrooms. International Journal of Research in Education and Science, 5(1), 331-345.

Fokides, E. (2018). Digital educational games and mathematics. Results of a case study in primary school settings. Education and Information Technologies, 23(2), 851-867. doi:10.1007/s10639-017-9639-5

Hainey, T., Connolly, T. M., Boyle, E. A., Wilson, A., \& Razak, A. (2016). A systematic literature review of games-based learning empirical evidence in primary education. Computers \& Education, 102, 202-223.

Hausman, N. L., Borrero, J. C., Fisher, A., \& Kahng, S. (2017). Teaching young children to make accurate portion size estimations using a stimulus equivalence paradigm. Behavioral Interventions, 32(2), 121132. doi:10.1002/bin.1466

Higgins, S., Beauchamp, G., \& Miller, D. (2007). Reviewing the literature on interactive whiteboards. Learning, Media and Technology, 32(3), 213-225. doi:10.1080/17439880701511040

Hollands, G. J., Shemilt, I., Marteau, T. M., Jebb, S. A., Lewis, H. B., Wei, Y., . . Ogilvie, D. (2015). Portion, package or tableware size for changing selection and consumption of food, alcohol and tobacco. Cochrane Database of Systematic Reviews(9). doi:10.1002/14651858.CD011045.pub2

Hyman, B. (2008). Integrating math and nutrition education: Teaching with the FDA food label. American Journal of Health Education, 39(2), 113-117. doi: 10.1080/19325037.2008.10599024

James, D. C., \& Adams, T. L. (1998). Curriculum integration in nutrition and mathematics. Journal of School Health, 68(1), 3-6.

Jones, A. M., \& Zidenberg-Cherr, S. (2015). Exploring nutrition education resources and barriers, and nutrition knowledge in teachers in California. Journal of Nutrition Education and Behavior, 47(2), 162-169. doi: 10.1016/j.jneb.2014.06.011

Karsenti, T. (2016). The Interactive Whiteboard (IWB): Uses, benefits, and challenges. A survey of 11,683 students and 1,131 teachers. Retrieved from Montreal: CRIFPE.

Ladwig, J., \& King, M. (2003). Quality teaching in NSW public schools: An annotated bibliography. Ryde: NSW Department of Education and Training Professional Support and Curriculum Directorate.

Larkin, K., \& Jorgensen, R. (2015). 'I hate maths: Why do we need to do maths?' Using iPad video diaries to investigate attitudes and emotions towards mathematics in Year 3 and Year 6 students. International Journal of Science and Mathematics Education, 14(5), 925-944. doi:10.1007/s10763-015-9621-x

Lowrie, T., \& Jorgensen, R. (Eds.). (2015). Digital games and mathematics learning: Potential, promises and pitfalls. Springer Netherlands.

Martin, A. J., Anderson, J., Bobis, J., Way, J., \& Vellar, R. (2012). Switching on and switching off in mathematics: An ecological study of future intent and disengagement among middle school students. Journal of Educational Psychology, 104(1), 1-18. doi:10.1037/a0025988

Milrad, M., Wong, L.-H., Sharples, M., Hwang, G.-J., Looi, C.-K., \& Ogata, H. (2013). Seamless learning: An international perspective on next-generation technology-enhanced learning $(\mathrm{Z}$. L. Berge \& L. Y. Muilenburg Eds.). New York: Routledge.

Min, K., \& Siegel, C. (2011). Integration of SMART board technology and effective teaching. i-Manager's Journal on School Educational Technology, 7(1), 38-47.

Muhanna, W., \& Nejem, K. M. (2013). Attitudes of mathematics teachers toward using smart board in teaching mathematics. Contemporary Issues in Education Research, 6(4), 373-380.

Nansen, B., Chakraborty, K., Gibbs, L., Vetere, F., \& MacDougall, C. (2012). 'You do the math': Mathletics and the play of online learning. New Media \& Society, 14(7), 1216-1235. doi:10.1177/1461444812442926

Nørnberg, T. R., Houlby, L., Jørgensen, L. N., He, C., \& Pérez-Cueto, F. J. A. (2014). Do we know how much we put on the plate? Assessment of the accuracy of self-estimated versus weighed vegetables and whole grain portions using an Intelligent Buffet at the FoodScape Lab. Appetite, 81, 162-167. doi:10.1016/j.appet.2014.06.007 
NSW Department of Education and Training. (2006). Quality teaching in NSW public schools: A classroom practice guide. Ryde: NSW Department of Education and Training Professional Support and Curriculum Directorate.

Oblinger, D. (2004). The next generation of educational engagement. Journal of Interactive Media in Education, 8(1). doi: 10.5334/2004-8-oblinger

Oenema, A., Brug, J., \& Lechner, L. (2001). Web-based tailored nutrition education: Results of a randomized controlled trial. Health Education Research, 16(6), 647-660.

Önal, N. (2017). Use of interactive whiteboard in the mathematics classroom: Students' perceptions within the framework of the technology acceptance model. International Journal of Instruction, 10(4), 67-86. doi:10.12973/iji.2017.1045a

Perera, T., Frei, S., Frei, B., Wong, S. S., \& Bobe, G. (2015). Improving nutrition education in US elementary schools: Challenges and opportunities. Journal of Education and Practice, 6(30), 41-50.

Pérez-Rodrigo, C., \& Aranceta, J. (2001). School-based nutrition education: Lessons learned and new perspectives. Public Health Nutrition, 4(1a), 131-139. doi:10.1079/PHN2000108

Perez-Rodrigo, C., \& Aranceta, J. (2003). Nutrition education in schools: Experiences and challenges. European Journal of Clinical Nutrition, 57(S1), S82-S85. doi:10.1038/sj.ejcn.1601824

Poelman, M. P., Steenhuis, I. H. M., de Vet, E., \& Seidell, J. C. (2013). The development and evaluation of an internet-based intervention to increase awareness about food portion sizes: A randomized, controlled trial. Journal of Nutrition Education and Behavior, 45(6), 701-707. doi:10.1016/j.jneb.2013.05.008

Prensky, M. (2003). Digital game-based learning. Computers in Entertainment, 1, 21-21.

Roseno, A. T., Carraway-Stage, V. G., Hoerdeman, C., Díaz, S. R., Geist, E., \& Duffrin, M. W. (2015). Applying mathematical concepts with hands-on, food-based science curriculum. School Science \& Mathematics, 115(1), 14-21. doi:10.1111/ssm.12097

Rosi, A., Scazzina, F., Ingrosso, L., Morandi, A., Del Rio, D., \& Sanna, A. (2015). The "5 a day" game: A nutritional intervention utilising innovative methodologies with primary school children. International Journal of Food Sciences and Nutrition, 66(6), 713-717.

Saathoff, C. (1991). Cooking with mathematics. The Mathematics Teacher, 84(9), 693-694.

Sahoo, K., Sahoo, B., Choudhury, A. K., Sufi, N. Y., Kumar, R., \& Bhadoria, A. S. (2015). Childhood obesity: Causes and consequences. Journal of Family Medicine and Primary Care, 4(2), 187-192. doi: $10.4103 / 2249-4863.154628$

Schifter, C. C., Cipollone, M., \& Moffat, F. (2013). Piaget, Inhelder and Minecraft. Paper presented at the International Conference on Cognition and Exploratory Learning in Digital Age.

Selwyn, N. (2010). Looking beyond learning: Notes towards the critical study of educational technology. Journal of Computer Assisted Learning, 26, 65-73. doi:10.1111/j.1365-2729.2009.00338.x

Shilts, M. K., Lamp, C., Horowitz, M., \& Townsend, M. S. (2009). Pilot study: EatFit impacts sixth graders' academic performance on achievement of Mathematics and English education standards. Journal of Nutrition Education and Behavior, 41(2), 127-131. doi: 10.1016/j.jneb.2008.05.007

Small, L., Lane, H., Vaughan, L., Melnyk, B., \& McBurnett, D. (2013). A systematic review of the evidence: The effects of portion size manipulation with children and portion education/training interventions on dietary intake with adults. Worldviews on Evidence-Based Nursing, 10(2), 69-81. doi:10.1111/j.17416787.2012.00257.x

Stage, V. C., Kolasa, K. M., Díaz, S. R., \& Duffrin, M. W. (2018). Exploring the associations among nutrition, science, and mathematics knowledge for an integrative, food- based curriculum. Journal of School Health, 88(1), 15-22. doi:10.1111/josh.12576

Statista. (2016, November). Number of mobile phone users worldwide from 2015 to 2020. Retrieved from https://www.statista.com/statistics/274774/forecast-of-mobile-phone-users-worldwide/

Steenhuis, I. H. M., \& Vermeer, W. M. (2009). Portion size: Review and framework for interventions. International Journal of Behavioral Nutrition and Physical Activity, 6, 58. doi:10.1186/1479-5868-6-58

Story, M. (1999). School-based approaches for preventing and treating obesity. International Journal of Obesity, 23(S2), S43-S51.

Strawser, C. L., \& Wachob, D. A. (2016). A review of current outcome measures for school health policy interventions. Health Behavior \& Policy Review, 3(1), 62-69. doi: 10.14485/HBPR.3.1.7

Sullivan, P. (2011). Teaching mathematics: Using research-informed strategies. Camberwell: Australian Council for Education Research. https://research.acer.edu.au/cgi/viewcontent.cgi?article=1022\&context=aer

Tan Sisman, G., \& Aksu, M. (2016). A study on sixth grade students' misconceptions and errors in spatial measurement: Length, area, and volume. International Journal of Science and Mathematics Education, 14(7), 1293-1319. doi:10.1007/s10763-015-9642-5 
Trucil, L. M., Vladescu, J. C., Reeve, K. F., DeBar, R. M., \& Schnell, L. K. (2015). Improving portion-size estimation using equivalence-based instruction. The Psychological Record, 65(4), 761-770. doi:10.1007/s40732-015-0146-Z

Tsinakos, A., \& Ally, M. (2013). Global mobile learning implementations and trends.

Tytler, R., Osborne, J., Williams, G., Tytler, K., \& Cripps Clark, J. (2008). Opening up pathways: Engagement in STEM across the primary-secondary school transition.

van der Bend, D., Bucher, T., Schumacher, T. L., Collins, K., De Vlieger, N., Rollo, M., . . . Collins, C. E. (2017). Trends in food and beverage portion sizes in Australian children; A time-series analysis comparing 2007 and 2011-2012 National data. Children, 4(8). doi:10.3390/children4080069

Van Eck, R. (2006). Digital game-based learning: It's not just the digital natives who are restless. EDUCAUSE review, 41(2), 16.

Verdine, B. N., Golinkoff, R. M., Hirsh-Pasek, K., Newcombe, N. S., Filipowicz, A. T., \& Chang, A. (2014). Deconstructing building blocks: Preschoolers' spatial assembly performance relates to early mathematical skills. Child Development, 85(3), 1062-1076. doi:10.1111/cdev.12165

$\mathrm{Vu}, \mathrm{P} .$, \& Feinstein, S. (2017). An exploratory multiple case study about using game-based learning in STEM classrooms. International Journal of Research in Education and Science, 3(2), 582-588. doi: 10.21890/ijres.328087

Wall, J. (2016). A Science, Technology, Engineering and Mathematics (STEM) review of the research. Scan: The Journal For Educators, 35(2), 27-41.

Wansink, B. (2004). Environmental factors that increase the food intake and consumption volume of unknowing consumers. Annual Review of Nutrition, 24, 455-479. doi:10.1146/annurev.nutr.24.012003.132140

Weber, J. L., Cunningham-Sabo, L., Skipper, B., Lytle, L., Stevens, J., Gittelsohn, J., . . Pablo, J. L. (1999). Portion-size estimation training in second- and third-grade American Indian children. The American Journal of Clinical Nutrition, 69(4), 782S-787S. doi:10.1093/ajcn/69.4.782S

Wilkinson, L., Sullivan, P., \& Jorgensen, R. (2009). 2009 futureSACE school to work Innovation program: Literacy \& Numeracy project final report.

Young, L. R., \& Nestle, M. (2007). Portion sizes and obesity: Responses of fast-food companies. Journal of Public Health Policy, 28(2), 238-248. doi:10.1057/palgrave.jphp.3200127

Young, L. R., \& Nestle, M. (2012). Reducing portion sizes to prevent obesity: A call to action. American Journal of Preventive Medicine, 43(5), 565-568. doi:10.1016/j.amepre.2012.07.024

Yu, C., Lee, S. J., \& Ewing, C. (2014). Mobile learning: Emerging trends, issues, and challenges in teaching and learning. Paper presented at the E-Learn: World Conference on E-Learning in Corporate, Government, Healthcare, and Higher Education, New Orleans, LA, USA. https://www.learntechlib.org/p/148925

\section{Author Information}

\section{Berit Follong}

University of Newcastle

School of Health Sciences

Faculty of Health and Medicine

University Drive

Callaghan, NSW 2308

Australia

\section{Elena Prieto-Rodriguez}

University of Newcastle

School of Education

Faculty of Education and Arts

University Drive

Callaghan, NSW 2308

Australia

\section{Clare Collins}

University of Newcastle

School of Health Sciences

Faculty of Health and Medicine

University Drive

Callaghan, NSW 2308

Australia

\section{Tamara Bucher}

University of Newcastle

School of Health Sciences

Faculty of Health and Medicine

University Drive

Callaghan, NSW 2308

Australia

Contact e-mail: tamara.bucher@newcastle.edu.au

\author{
Andrew Miller \\ University of Newcastle \\ School of Education \\ Faculty of Education and Arts \\ University Drive \\ Callaghan, NSW 2308 \\ Australia
}




\section{Appendix. Teacher Survey}

Thank you very much for your interest in participating in this research!

With this survey, we would like to find out about your teaching practices in mathematics, particularly in the area of volume and capacity.

The survey will take about 10 minutes.

Your contribution would be highly appreciated!

Best regards,

The study team

Miss Berit Follong, Dr Tamara Bucher, Dr Elena Prieto-Rodriguez, Dr Drew Miller and Professor Clare Collins

To read more about the study and what it involves, please proceed to the information statement by clicking 'next'.

Information Statement for the Research Project:

Teaching measurements in Australian Primary Schools

Dear reader,

You are invited to participate in the research project identified above which is being conducted by a team of University of Newcastle researchers. The research is part of Berit Follong's PhD studies at the University of Newcastle, supervised by Dr Tamara Bucher, and Professor Clare Collins from the School of Health Sciences, and Dr Elena Prieto-Rodriguez and Dr Drew Miller from the School of Education.

\section{Why is the research being done?}

The purpose of this survey is to investigate current mathematics teaching practices especially on volume measurements in primary schools and what resources teachers use to address volume measures in class. In addition, we aim to understand the teacher's use/attitude towards technology/games used during their mathematical lessons.

The survey will provide the research team with essential information to progress towards a mathematics and nutrition education intervention study aimed at the primary school curriculum.

\section{Who can participate in the research?}

Teachers who currently teach or have ever taught Year 3 and/or 4 at an Australian primary school.

What would you be asked to do?

If you agree to participate, you will be asked to complete an online survey created by the research team. This survey will take approximately 10 minutes and comprises of 21 questions regarding your teaching practices in mathematics education with a focus on volume and capacity measurements. The survey can be completed at any time and place the teacher prefers.

\section{What choice do you have?}

Participation in this research is entirely your choice. Only those people who give their informed consent will be included in the project. Whether or not you decide to participate, your decision will not disadvantage you.

If you do decide to participate, you may withdraw from the project at any time (e.g. up to the point of submission) without giving a reason and have the option of withdrawing any data which identifies you.

What are the risks and benefits of participating?

There will be no risks associated with participating in this research. Whilst there are no anticipated benefits to you personally in participating in this research, the findings will help contribute to developing a future mathematics and nutrition educational game. 


\title{
How will your privacy be protected?
}

The results of the study will be published in general terms and will not allow the identification of individual teachers or schools. Once the data has been collected, it will be exported into an electronic data file. Paper surveys will be entered into the electronic file and destroyed. Data will be stored for at least 5 years on password protected files that can only be directly accessed by the researchers. Non-identifiable data may also be shared with other parties to encourage scientific scrutiny, and to contribute to further research and public knowledge.

\section{How will the information collected be used?}

The data collected from this survey will be used for journal publications, conference presentations and to inform future practice for the design of valuable, evidence-based mathematics education programs. Furthermore, the data will be reported in a thesis to be submitted for Ms Berit Follong's PhD degree. Individual participants will not be identified in any reports arising from the project. If you would like a copy of the summary of the results, please email Miss Berit Follong (berit.follong@uon.edu.au) after 1st of May 2018.

\section{What do you need to do to participate?}

Please read this Information Statement and be sure you understand its contents before you consent to participate. If there is anything you do not understand, or you have questions, contact the researcher.

If you would like to participate, please click the "Next" button to proceed to the accompanying survey. Completion of the online survey will be taken as your informed consent to participate.

\section{Further information}

If you would like further information please contact Miss Berit Follong (berit.follong@uon.edu.au).

Thank you for considering this invitation.

\author{
Miss Berit Follong \\ PhD Candidate \\ School of Health Sciences \\ Faculty of Health and Medicine \\ University of Newcastle \\ Callaghan NSW 2308 \\ Phone: + 61(0)2 49215453 \\ Email: Berit.follong@uon.edu.au \\ Dr Tamara Bucher \\ School of Health Sciences \\ Faculty of Health and Medicine \\ University of Newcastle \\ Callaghan NSW 2308 \\ Phone: + 61 (0)2 49816608 \\ Email: tamara.bucher@newcastle.edu.au
}

\section{Complaints about this research}

Should you have concerns about your rights as a participant in this research, or you have a complaint about the manner in which the research is conducted, it may be given to the researcher, or, if an independent person is preferred, to the Human Research Ethics Officer, Research Services, NIER Precinct, The University of Newcastle, University Drive, Callaghan NSW 2308, Australia, telephone (02) 4921 6333, email HumanEthics@newcastle.edu.au.

This project has been approved by the University's Human Research Ethics Committee, Approval No. H-20180067. 
I have read the information on the previous page and would like to participate in the study. Hereby, I consent that my answers can be used for research purposes.

Yes

No

We care about the quality of our survey data and hope to receive the most accurate measures of your opinions, so it is important to us that you thoughtfully provide your best answer to each question in the survey.

Do you commit to providing your thoughtful and honest answers to the questions in this survey?

I will provide my best answers

I will not provide my best answers

I can't promise either way

The first part of the survey consists of questions about you, your teaching background and your current teaching environment.

Do you currently teach or have you ever taught Year 3 and/or 4 mathematics?
Yes
No

What is your year of birth?

What is your gender?

Male

Female

Other 
Where do you teach (or did you last teach) Year 3 and/or 4 mathematics in Australia?

ACT
NSW
NT
QLD
SA
TAS
VIC
WA
None of the above

How many years of experience in teaching primary school mathematics do you have?

$0-2$ years

3-5 years

6-10 years

11-15 years

$16+$ years

What is the approximate size of the school you teach (or last taught) at?

$<100$ students

$101-200$ students

201-300 students

301-400 students

$>400$ students

What kind of school do you teach (or did you last teach) at?

\section{Government school}

Non-government school (Catholic).

Non-government school (Independent). 
The following questions will ask you about your teaching practices in mathematics.

How often do you use the following resources when teaching volume and capacity?

\begin{tabular}{|c|c|c|c|c|c|}
\hline $\begin{array}{c}\text { 4-5 times a } \\
\text { week }\end{array}$ & $\begin{array}{l}\text { 2-3 times a } \\
\text { week }\end{array}$ & $\begin{array}{l}\text { Once a } \\
\text { week }\end{array}$ & $\begin{array}{l}1-3 \text { times a } \\
\text { month }\end{array}$ & $\begin{array}{c}\text { Less than } \\
\text { once a } \\
\text { month }\end{array}$ & Never \\
\hline
\end{tabular}

Books

Video/film

PowerPoint slides

Online information websites/games

Cubes/blocks

Containers

Household measures (e.g. measuring cups/spoons/pitchers)

Liquids

Food

Smart board

Tablets/Ipads

Phones

Computer

Other: 
Do you use any of the following nutrition-related examples when teaching volume and capacity? (Multiple answers allowed)

\section{Cooking/recipes}

Household measures (e.g. measuring cups/spoons/pitchers)

Grocery shopping/supermarket products

Food labels

I don't usually use nutrition-related examples

Other

Do you make use of digital games when teaching volume and capacity? If yes, please indicate which digital game you use.

Yes, I use the following digital game(s)

No, but I would like to make use of digital games

No, and I would not like to make use of digital games

I don't know

In your opinion, what characteristics would you like in digital games to teach volume and capacity? 
Do you believe that digital games designed for mathematics education in primary schools could increase a child's:

Definitely yes Probably yes $\begin{gathered}\text { Might or might } \\ \text { not }\end{gathered}$
Achievement in
Mathematics
Learning
enjoyment
Knowledge
about
Mathematics

When teaching mathematics, do you integrate this with the following other learning areas of the Australian curriculum?

Yes $\quad$ No

English

Science

Humanities and Social Sciences

Arts

Technologies

Health and Physical Education

Languages

When integrating mathematics with $\$\{1 \mathrm{~m}: / /$ Field $/ 1\}$, which resources do you use for this? 
How useful do you believe it would be to have a digital game to integrate volume and capacity (within the Mathematics curriculum) with nutrition (within the Health and Physical Education curriculum)?

Extremely useful

Very useful

Moderately useful

Slightly useful

Not at all useful

Do you have any additional comments about the survey? 